\title{
Climate Forecast and Decision Making in Agriculture ${ }^{1}$
}

\author{
Clyde Fraisse, David Zierden, Norman Breuer, John Jackson, and Charles Brown ${ }^{2}$ \\ Farmers make decisions on a daily basis that

\section{Can Climate Be Predicted?} affect their financial returns and overall welfare. The consequences of decisions are often not known with certainty until long after the decisions occur and the outcomes can be better or worse than expected. Often the decisions are made based on some type of forecast, such as price, weather, or climate. Price-based decisions are associated with changes in the price of output or of inputs that may eventually occur and require a broad understanding of markets both domestic and international. Weather is the atmosphere changing from day-to-day: a rainstorm or cold snap. Weather-based decisions are generally operational by nature and involve activities that should happen in the very near future, most of the time in less than a week. Examples are irrigation, freeze protection, fertilizing, and harvesting. Climate can refer to a wet, cool winter or a hot, dry summer. Climate-based decisions are normally pre-season decisions and tend to be more strategic in nature. Examples of climate-based decisions can be the choice of variety planted, acreage allocation, pre-season purchase of inputs, and marketing.
Weather forecasts are usually fairly accurate in terms of predicting the significant weather features for the coming 1 to 2 days. However, the accuracy of weather forecasts decreases as the lead time increases to $3,4,5$ or more days. A forecast for 4 days into the future, for example, often needs to be revised as that day approaches, and in some cases the revision may be large. Is it possible, then, to make useful climate forecasts for some regions for the coming three months, and sometimes even for the 3-month period following that?

The ability to predict climate has improved in recent years and there have been significant and increasing efforts devoted in various parts of the world to apply climate information for improving agricultural systems (Jagtap et al., 2002). In spite of improvements in the ability to predict climate, it is still not possible to forecast before the season on which day a locality will have precipitation, storms, temperature extremes, frontal passages, and so forth. However, scientists have developed some ability in predicting anomalies in the seasonal average of the weather, (i.e., anomalies of the climate). The total

1. This document is ABE 352, one of a series of the Agricultural and Biological Engineering Department, Florida Cooperative Extension Service, Institute of Food and Sciences, University of Florida. Published July 2004. Please visit the EDIS Web site at http://edis.ifas.ufl.edu.

2. Clyde Fraisse, Assistant Extension Scientist, Agricultural and Biological Enginerering Department, University of Florida; David Zierden, Assistant State Climatologist, Center for Ocean-Atmospheric Prediction Studies, Florida State University; Norman Breuer, PhD, Southeast Climate Consortium; John L. Jackson, Jr., Extension Agent IV, Lake County Cooperative Extension, University of Florida; and Charles M. Brown, Coordinator for Information/Publication Services, Agricultural and Biological Engineering Department, University of Florida.

The Institute of Food and Agricultural Sciences (IFAS) is an Equal Employment Opportunity - Affirmative Action Employer authorized to provide research, educational information and other services only to individuals and institutions that function without regard to race, creed, color, religion, age, disability, sex, sexual orientation, marital status, national origin, political opinions or affiliations. For information on obtaining other extension publications, contact your county Cooperative Extension Service office. Florida Cooperative Extension Service / Institute of Food and Agricultural Sciences / University of Florida / Larry R. Arrington, Interim Dean 
rainfall, for example, may be predicted to be higher than the climatological average for a given location. Again, the timing of the rainfall events remains unknown.

Much of the ability in predicting departures from normal seasonal totals or averages has its origin in the slowly changing conditions at the earth's surface that can influence the climate. The most important surface condition affecting climate is the sea surface temperature (SST), and particularly the SST in the tropical zones. Other, usually less influential, surface conditions are soil wetness and snow cover. The feature of the surface conditions that gives them the ability to influence average weather conditions over an extended future period is the slowness with which they can change, and therefore, the extended period over which they can exert their consistent influence. When the SST is higher than normal, it usually remains that way for several months, and sometimes for as long as a year or more, such as during El Niño or La Niña events in the tropical Pacific SST.

\section{What Are El Niño and La Niña?}

The El Niño-Southern Oscillation (ENSO) phenomenon is the strongest driver of interannual climate variability around the world and its impact on the climate of Florida is well documented. When sea surface temperature in the eastern equatorial Pacific Ocean is higher than normal the phenomenon is referred to as El Niño. When the temperature is lower than normal the phenomenon is referred to as $\mathrm{La}$ Niña. When the temperature is normal, the event is referred to as Neutral. El Niño normally brings $30 \%-40 \%$ more rainfall and cooler temperatures during fall and winter, while La Niña brings a warmer and drier than normal fall and winter. Florida also gets few Atlantic hurricane landfalls during El Niño years. An important finding was that of the 12 major winter freezes in central Florida that occurred in the last century, 11 were during Neutral phases.

Each El Niño, La Niña or Neutral year is defined as beginning in October and running through September of the next calendar year. By monitoring the sea surface temperature in the tropical Pacific Ocean, we can know in advance what type of climate is developing for the year. Although El Niño and La
Niña return every 2 to 7 years, the majority of the time the tropical Pacific is neutral. One can expect $50 \%$ of the years to be neutral, $25 \%$ El Niño and $25 \%$ La Niña

\section{How to Interpret Climate Forecasts}

Climate forecasts are generally presented in terms of probabilities since it is not possible yet to predict the exact amount of rainfall or the seasonal temperature range. Normally, it is given the probability or chance that a certain range of rainfall or temperature is expected to occur in the coming months (frequency probability).

Figure 1 shows the probability of occurrence for various ranges of rainfall for the month of January in Jackson County, Florida. The top graph shows the probabilities calculated by using all years of data available for the local meteorological station. It can be noticed that there is a probability of about $14 \%$ that the total rainfall in January will be only 3 inches. Probabilities for total rainfall of 4, 5, and 6 inches are of $15.1,14.2$ and 12.5 percent, respectively.

The question to be asked is: Will the probabilities change if the year ahead is an El Niño, La Niña, or Neutral year? The bottom graph clearly indicates significant changes according to ENSO phases. It can be observed that the probability for only 3 inches of total rainfall increases significantly during La Niña years to about $25 \%$ and decreases during El Niño years to about $8 \%$. In general, the probabilities for less rainfall in January are much higher during La Niña years and lower during El Niño years. Conversely, the probabilities for greater amounts of rainfall are higher during El Niño years.

Another way to present forecast probabilities is to plot probabilities of exceedance (figure 2). The histograms associated with a probability of exceedance may be easier to interpret since they explicitly relate probabilities and climate thresholds, that means that the probability of occurring "at least" a certain threshold of a climate variable. Figure 2 shows the probabilities of exceedance for various ranges of rainfall for the month of January in Jackson County, Florida during El Niño, La Niña, and neutral years. 

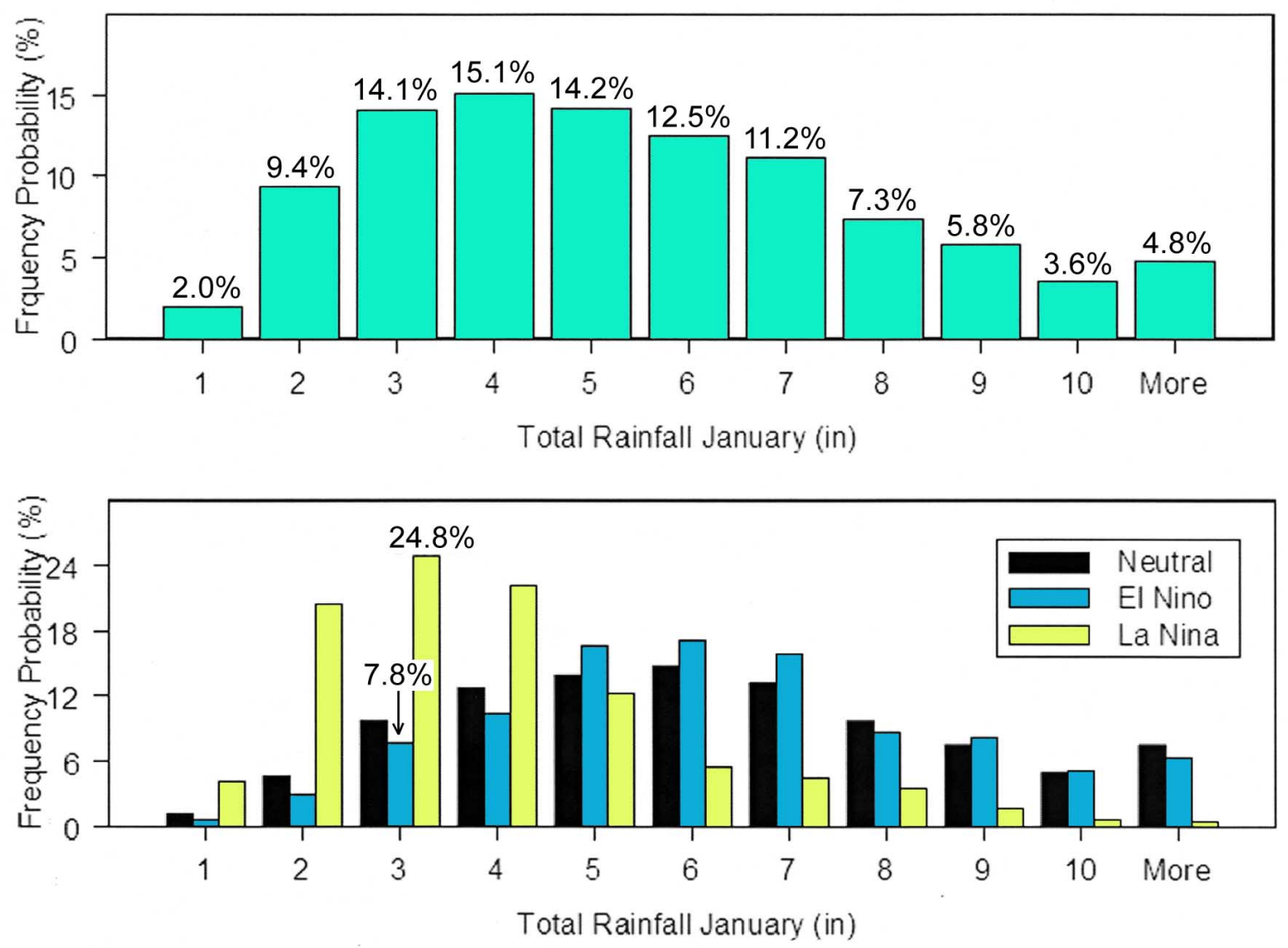

Figure 1. Frequency probabilities for total rainfall in January during all years (top) and Neutral, El Niño, and La Niña years (bottom).

When we average the January rainfall for all years in the historical data used for this analysis, the probability of raining at least 4-5 inches in January is 59.4\%. However, when only El Niño years are averaged, this probability increases to $78.1 \%$, much higher than during a La Niña year (28.3\%).

An example of the practical application of this information can be helpful. Suppose a winter pasture needs at least 5 inches of rainfall in January to have excellent growth and development. The chances of 5 inches of rainfall and therefore achieving optimal growth are about $78.1 \%$ in El Niño years, almost 50 percentage points higher than in La Niña years.

Both ways to present climate forecasts (frequency probability and probability of exceedance) may be of interest to growers' decision-making processes.

\section{Climate of Florida}

Climate is Florida's most important physical resource, a fact well recognized by its citizens, whose state government has officially designated Florida "the Sunshine State" (Winsberg 2003). In reality, the western, arid part of the United States has many more hours of sunshine than Florida. However, Florida has approximately double the amount of hours of sunlight than the states in the northeastern quadrant of the nation, and far milder temperatures. Mild and sunny winters are Florida's greatest physical asset, and without these climate elements, it would be far less attractive to visitors as well as both young and older migrants. Florida's agriculture, heavily based on winter warmth, supplies not only citrus but also winter vegetables to the rest of the nation.

Most of Florida lies within the extreme southern portion of the Northern Hemisphere's humid subtropical climate zone, noted for its long hot and 

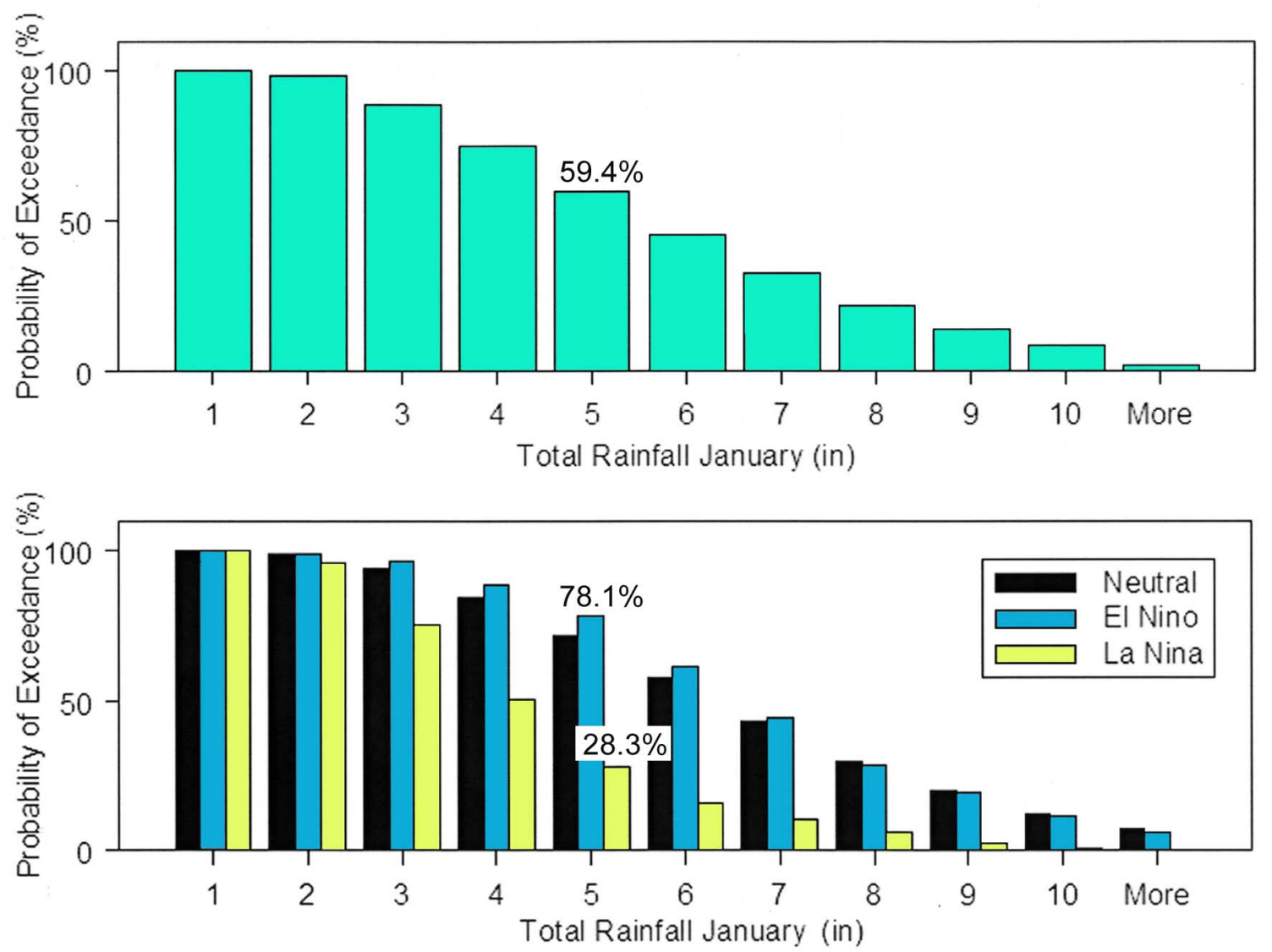

Figure 2. Probabilities of exceedance for all years (top) and neutral, El Niño and La Niña years (bottom).

humid summers and mild and wet winters. The southern-most portion of the state is generally designated as belonging to the tropical savanna region, a climate that it shares with most of the Caribbean islands. Sometimes also called the wet and dry tropics, tropical savanna precipitation is highly concentrated in the warmer months.

The main factors governing Florida's climate are latitude, land and water distribution, prevailing winds, storms and pressure systems, and ocean currents. Although no place in Florida is far from sea level, during the winter, altitude can be a significant local factor in affecting temperature. Early grove owners quickly learned that the citrus trees they planted in depressions were much more susceptible to freezes than those that were planted on higher ground.

Florida is divided into 7 Climate Divisions (figure 3). Each division contains multiple temperature and precipitation monitoring stations. Unweighted arithmetic means of monthly data were taken from all stations within a given division that are thought to reflect the general climatic characteristics of the division, although there are climate variations within the divisions. Table 1 shows the average rainfall per month for each climate division and the mean temperature for each month and each climate division.

Mean average temperatures during Florida's coldest month (January) range from the lower 50s in the north (Climate Divisions 1 and 2) to the high 60s in the south (Climate Divisions 6 and 7). In the hottest month (usually July, but in places August), average temperatures are almost the same throughout the entire state, between $81^{\circ} \mathrm{F}$ and $84^{\circ} \mathrm{F}$.

Temperatures during the year in Florida are heavily influenced by the Gulf of Mexico and the Atlantic Ocean with the greatest effects near the coast. Land and water differ in their ability to absorb and reflect heat. Land, when exposed to the same amount of heat as a body of water, will heat more 
rapidly than the water surface and will attain a higher temperature. Since Florida is mainly a long peninsula, no place in the state is more than 80 miles from the Gulf of Mexico or the Atlantic Ocean. The surface water temperature in both the Gulf of Mexico and the Atlantic Ocean rises to about $84^{\circ} \mathrm{F}$ in the summer and falls to about $70^{\circ} \mathrm{F}$ in the winter.

Florida is among the wettest states in the U.S., with most areas receiving at least 50 inches of rain annually (Black, 1993). The Panhandle and southeastern Florida are the two wettest parts of the state (Climate Divisions 1 and 6). The driest are the Florida Keys (Climate Division 7) and the offshore bar of Cape Canaveral. The Panhandle receives so much rain because it has two wet seasons, one during Winter, when fronts pass through bringing rain, and the other in Summer, when convectional rain falls. Frontal precipitation plays an increasingly smaller role in annual precipitation the farther one goes down the peninsula. Half of the Panhandle precipitation occurs during the hot months between May and August; in Central Florida, summer precipitation is between 60 and 65 percent of the yearly total. In the Keys and the extreme southwestern peninsula, it rises to over 70 percent. Coastal locations, including the Keys, receive less rain than nearby, more interior areas because coastal areas do not provide as good an environment for convectional heating.

\section{Climate Forecast Applications to Agriculture in Florida}

Previous research into potential applications of long-lead seasonal forecasts in Florida indicated that a number of agricultural related industries could benefit from climate forecasts. Previous work focusing on lawn management (Miller et al., 2001), tomato (Breuer et al., 2004) and several row crops has indicated potential benefits of climate-based decision-making strategies.

Climate forecast has also been used to recommend planting of winter pastures to livestock producers in the Florida Panhandle. The Jackson County Extension Livestock and Forage Newsletter (Vol. 3, No, 3; Fall 2002) highlighted the coming El Niño phase and associated increased winter rainfall as a potential opportunity for good pasture production. In addition, it also warned about the potential for low areas getting too wet for small grains. A potato farmer in South Florida also commented about increased productivity by taking simple actions such as cleaning the field drains prior to El Niño to better handle the increase in winter rainfall.

Usefulness of climate forecast is associated with both timing and accuracy of the forecast. A perfect forecast will be useless if delivered to a stakeholder after the window of time for making decisions. The same may be true for an inaccurate forecast delivered within the decision time window. However, accuracy is a concept that deserves further discussion since forecasts are probabilistic in nature and by definition are correct most of the time. The fact that a low or very low probability event happens doesn't mean that the forecast was wrong, in spite of unwanted consequences. One must recognize that interpretation of forecasts and their associated risks is as important as the forecast themselves.

Identification of both the kinds of decisions that can benefit from climate forecasts in several agricultural sectors and the type of forecast required are first steps toward implementation of dynamic and relevant climate services in Florida. Table 3 lists a number of decisions that can take advantage of climate forecasts within three agriculture-related industries.

The Southeast Climate Consortium (SECC), formed by six universities in Alabama, Florida, and Georgia, is implementing a Web-based decision aid system (http://www.agclimate.org) to provide Extension agents, farmers, and natural resource managers with tools to reduce risks associated with climate variability. The AgClimate Web site comprises climate forecast for the southeastern region and management guidelines for the most important agricultural commodities in the region, including land preparation, varieties and general cultural practices recommendations. It also includes model-based crop yield risk analysis tools and historical impacts of climate variability on selected commodities. 


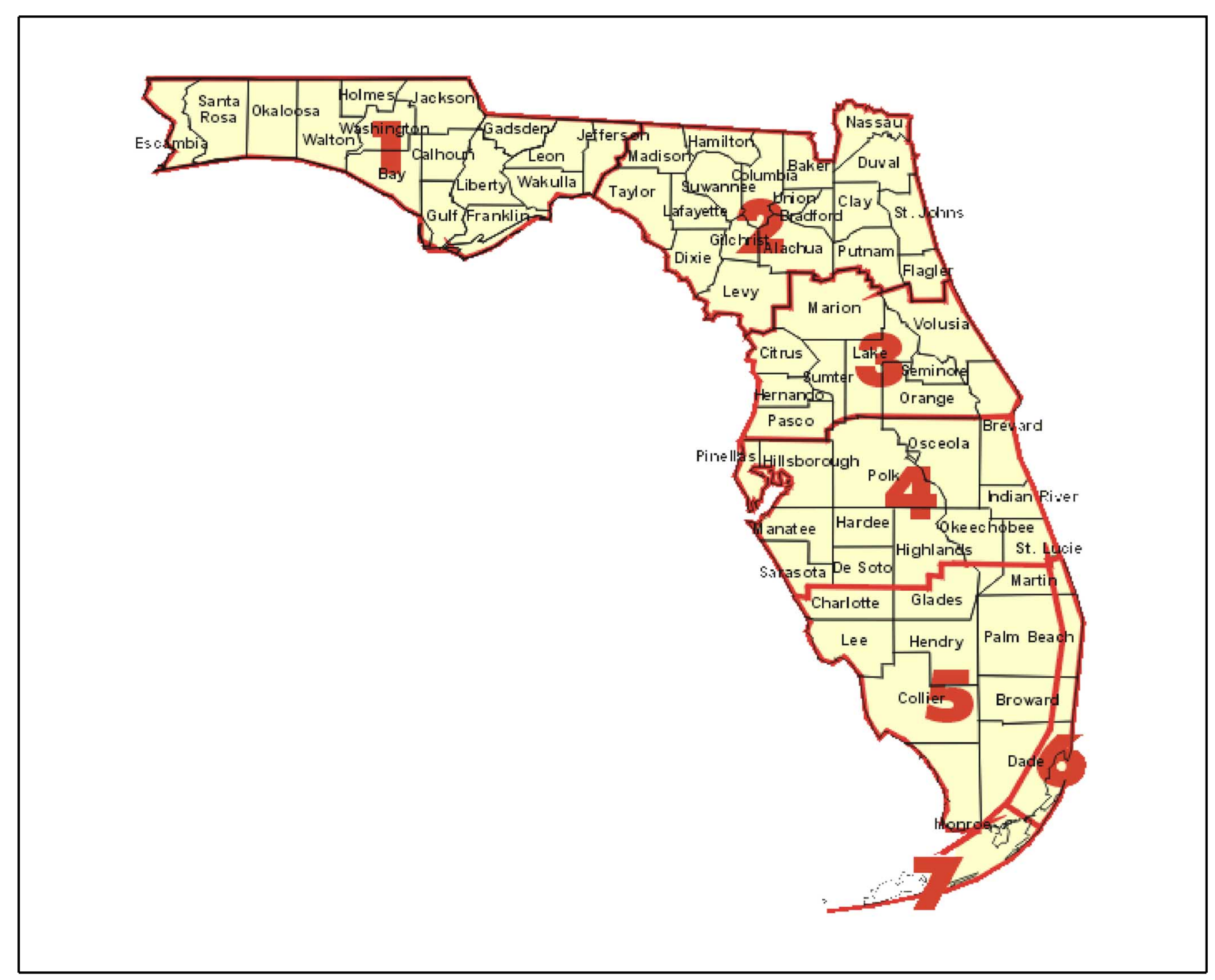

Figure 3. Florida's climate divisions.

\section{References}

Black, R. J. 1993. Florida Climate Data (IFAS Publication Circular EES-5). Florida Cooperative Extension Service, Institute of Food and Agricultural Sciences, University of Florida, Gainesville.

Breuer, N., Gilreath, P. , McAvoy, G.M., Letson, D., and Fraisse, C. 2004. Using Seasonal Climate Variability Forecasts: Risk Management for Tomato Production in South Florida. Fliorida Cooperative Extension Service, Gainesville, Florida. IFAS Publication CIR 1450.

Jagtap, S. S., Jones, J.W., Hildebrand, P., Letson, D., O'Brien, J.J., Podesta, G., Zierden, D., and Zazueta, F. 2002. Responding to Stakeholder
Demands to Climate Information: From Research to Applications in Florida. Agricultural Systems 77:415-430.

Miller, G.L., Park-Brown, S., Stiles, C., Dukes, M., Royce, F., Jones, J.W., Zazueta, F.S., and Zierden, D. 2001. Climate-based Management of Lawns. Florida Cooperative Extension Service, Gainesville, Florida. IFAS Publication AE319.

Winsberg, B., Zierden, D., and O'Brien, J. 2003. Climate of Florida. NOAA-NCDC Clim60 Publication Series. 
Table 1. Rainfall and Temperature Averages by Month for Each Climate Division in Florida.

\begin{tabular}{|c|c|c|c|c|c|c|c|c|c|c|c|c|c|}
\hline \multirow{2}{*}{$\begin{array}{l}\text { Climate } \\
\text { Division }\end{array}$} & \multicolumn{13}{|c|}{ Average Rainfall Totals (in) } \\
\hline & Jan & Feb & Mar & Apr & May & Jun & Jul & Aug & Sep & Oct & Nov & Dec & Total. \\
\hline 1 & 5.74 & 4.73 & 6.29 & 3.76 & 4.32 & 6.13 & 7.95 & 6.66 & 5.73 & 3.53 & 4.20 & 4.09 & 63.13 \\
\hline 2 & 4.20 & 3.43 & 4.48 & 3.10 & 3.30 & 6.16 & 6.73 & 7.22 & 5.81 & 3.34 & 2.55 & 3.03 & 53.35 \\
\hline 3 & 3.20 & 2.92 & 3.96 & 2.56 & 3.64 & 6.87 & 6.94 & 7.12 & 6.21 & 3.02 & 2.58 & 2.56 & 51.58 \\
\hline 4 & 2.58 & 2.69 & 3.32 & 2.23 & 3.65 & 7.03 & 7.24 & 7.54 & 6.81 & 3.29 & 2.43 & 2.27 & 51.08 \\
\hline 5 & 2.19 & 2.02 & 2.60 & 2.27 & 4.31 & 8.34 & 7.27 & 7.69 & 7.08 & 3.50 & 2.28 & 1.71 & 51.26 \\
\hline 6 & 2.62 & 2.44 & 2.91 & 3.33 & 5.67 & 8.51 & 6.14 & 7.70 & 8.15 & 5.81 & 3.97 & 2.41 & 59.66 \\
\hline 7 & 2.39 & 1.66 & 2.14 & 1.97 & 3.53 & 5.63 & 3.35 & 5.29 & 6.06 & 4.89 & 2.71 & 2.05 & 41.67 \\
\hline \multirow{2}{*}{$\begin{array}{l}\text { Climate } \\
\text { Division }\end{array}$} & \multicolumn{13}{|c|}{ Mean Temperature $\left({ }^{\circ} \mathrm{F}\right)$} \\
\hline & Jan & Feb & Mar & Apr & May & Jun & Jul & Aug & Sep & Oct & Nov & Dec & Avg. \\
\hline 1 & 50.5 & 54.3 & 60.4 & 66.3 & 73.7 & 79.4 & 81.4 & 80.9 & 77.4 & 67.9 & 60.0 & 52.7 & 67.0 \\
\hline 2 & 53.6 & 57.3 & 62.9 & 67.9 & 74.7 & 79.7 & 81.6 & 81.2 & 78.3 & 70.4 & 63.0 & 55.8 & 68.6 \\
\hline 3 & 58.3 & 61.2 & 66.1 & 70.2 & 76.1 & 80.3 & 81.7 & 81.6 & 79.9 & 73.5 & 66.9 & 60.5 & 71.1 \\
\hline 4 & 61.2 & 63.7 & 67.8 & 71.4 & 76.8 & 80.6 & 81.9 & 82.0 & 80.7 & 75.4 & 69.2 & 63.3 & 72.5 \\
\hline 5 & 63.8 & 65.9 & 69.6 & 72.9 & 77.6 & 81.1 & 82.3 & 82.4 & 81.5 & 77.0 & 71.5 & 66.0 & 74.2 \\
\hline 6 & 67.1 & 68.6 & 71.7 & 74.5 & 78.4 & 81.3 & 82.5 & 82.8 & 81.9 & 78.7 & 73.9 & 69.4 & 75.4 \\
\hline 7 & 69.8 & 70.5 & 73.3 & 76.6 & 80.3 & 82.9 & 84.3 & 84.2 & 83.0 & 79.7 & 75.8 & 71.4 & 77.7 \\
\hline
\end{tabular}

Table 2. Climate Characteristics of Seasons for Netural, El Niño, and La Niña Years.

\begin{tabular}{||c|c|c|c|c||}
\hline \hline \multirow{2}{*}{$\begin{array}{c}\text { Climate } \\
\text { Phase }\end{array}$} & \multicolumn{4}{|c||}{ Season } \\
\cline { 2 - 5 } & Oct-Dec & Jan-Mar & Apr-Jun & Jul-Sep \\
\hline El Niño & Wet & Strong Wet & Weak Dry & Normal \\
& Cool & Strong Cool & Weak Wet & Normal \\
& Dry & Strong Dry & Woak Cool \\
\hline La Niña & Weak Warm & Strong Warm & Normal & Normal \\
\hline
\end{tabular}


Table 3. Examples of Decisions That Can Take Advantage of Pre-season Climate Forecasts.

\begin{tabular}{||l|l|l||}
\hline \hline Sector & \multicolumn{1}{|c|}{ Decision } & \multicolumn{1}{|c||}{ Forecast Required } \\
\hline Field \\
Crops & Select variety & Rainfall and temperature \\
\cline { 2 - 3 } & Decide about acreage allocation & Rainfall and temperature \\
\cline { 2 - 3 } & Anticipate purchase of fungicides & Rainfall and temperature \\
\cline { 2 - 3 } & Order more or less herbicide & Rainfall \\
\cline { 2 - 3 } & $\begin{array}{l}\text { Apply more or less fertilizer (or change number and/or } \\
\text { distribution of applications) }\end{array}$ & Rainfall \\
\cline { 2 - 3 } & Sell or hold grain stocks & Rainfall \\
\cline { 2 - 3 } & Strategize marketing & Rainfall and temperature \\
\hline \multirow{5}{*}{ Livestock } & Plant winter forage & Rainfall and Temperature \\
\cline { 2 - 3 } & Anticipate feed purchase to avoid high prices & Rainfall and Temperature \\
\cline { 2 - 3 } & Stocking rates & Rainfall and Temperature \\
\hline \multirow{5}{*}{ Forestry } & Plant drought resistant/vulnerable seedlings & Rainfall \\
\cline { 2 - 3 } & Schedule timber harvest of floodable stands & Rainfall \\
\cline { 2 - 3 } & Schedule timber harvest of high / dry areas & Rainfall \\
\cline { 2 - 3 } & Resource for forest fire monitoring & Rainfall \\
\hline \hline
\end{tabular}

